\title{
Profiling research of the engineering academics who successfully promote education in Sustainable Human Development
}

\author{
Boris Lazzarini $^{\mathrm{a}}$, Agustí Pérez-Foguet ${ }^{\mathrm{b}}$ \\ ${ }^{a}$ Universitat Politècnica de Catalunya-BarcelonaTech, Research Institute of Sustainability Science and \\ Technology, Engineering Sciences and Global Development (EScGD) Research Group, c/ Jordi Girona \\ 31,Ed.TG-S1,08034 Barcelona, Spain, boris.lazzarini@upc.edu (correspondent author) \\ ${ }^{b}$ Universitat Politècnica de Catalunya - BarcelonaTech, School of Civil Engineering, Department of \\ Civil and Environmental Engineering, Research Institute of Sustainability Science and Technology, \\ Engineering Sciences and Global Development (EScGD) Research Group, c/ Jordi Girona 1-3, C2 310, \\ 08034 Barcelona, Spain, agusti.perez@upc.edu
}

Keywords: Sustainable Development, Bibliometrics, Global Dimension, Engineering, Interdisciplinary Research.

\begin{abstract}
Over the last decades, engineering faculties and universities have become increasingly engaged in integrating sustainable development into their different functions. Notwithstanding, more effort is required to effectively integrate sustainability principles as a whole-university approach, and specifically, in technical universities. Scientific literature highlights the main barriers to the success of initiatives that address this shortcoming. A better understanding of the scientific profile of the academics who engage in sustainable development activities can help to develop and promote initiatives for increasing faculty engagement in all academic functions. For this purpose, this study presents a bibliometric analysis of the scientific production of an academic community involved in a European initiative aimed at capacitating engineering academics for sustainable development. Specifically, two groups of academics with different degrees of expertise and involvement in sustainable development were characterized and compared, revealing common trends and similarities of their research production. The results have different implications for future strategies aimed at engaging specific academic profiles in the field of engineering, highlighting especially health science-related fields linked with engineering as a potential opportunity of promoting the integration of sustainable development in engineering education. Further analysis is required to determine the university rankings and their potential implications for the integration of sustainable development, as well as appropriate policies and mechanisms of faculty rewarding and promotion.
\end{abstract}


Non-standard abbreviations:

ARWU: Academic Ranking of World Universities;

ENG: Engineering/Technology and Computer Sciences;

ESD: Education for Sustainable Development;

GDEE: Global Dimension in Engineering Education;

HEI: Higher Educational Institutions;

IDR: Interdisciplinary Research;

LIFE: Life and Agriculture Sciences;

MED: Clinical Medicine and Pharmacy;

NGO: Non-Governmental Organisation;

SCI: Natural Sciences and Mathematics;

SD: Sustainable Development;

SHD: Sustainable Human Development;

SOC: Social Sciences;

WoS: Web of Science. 


\section{Highlights:}

- Engineering academics involved in sustainable development show high interdisciplinarity

- University rankings may represent a barrier to integrating sustainable development

- Linking engineering and health sciences could promote sustainable human development 


\section{Introduction}

In the last two decades, the advances in global sustainable development (SD) have been unprecedented. Among the main achievements worth highlighting include: the profound decline of extreme poverty and child mortality; the high increase of life expectancy and human health in developing contexts; the rise of literacy rates among youth; and important achievements in environmental sustainability (United Nations, 2015a). Nevertheless, the international development policies promoting SD have not produced adequate and effective solutions to the problems of global inequality. In fact, we still have large gaps between the poorest and the richest, social and gender inequalities, environmental degradation, and climate change, which pose critical challenges for the global community and future generations (United Nations, 2015b). Within this context, major transformations and systemic changes need to be promoted in different societal spheres (Wals, 2014).

A major challenge for higher education is to contribute to transforming the global society into a more sustainable and equitable one. Indeed, higher education institutions (HEI) should play a significant role in promoting $\mathrm{SD}$, since they have an incomparable role, through their academic function, in educating and preparing the future leaders and decision-makers (Sammalisto et al., 2015). During the last decades, several initiatives and approaches aimed at integrating SD in HEI at different levels have been successfully promoted (Lozano et al., 2015, 2013a; Ramos et al., 2015). Furthermore, scientific paradigms and education theories in HEI have underwent dramatic changes related to the processes of societal transformation towards SD (Dlouhá et al., 2013). Nevertheless, it has been argued that education for sustainable development (ESD) has not fully permeated university culture (Lozano et al., 2013b; Mulder et al., 2012).

Obtaining changes towards a culture of sustainability in universities have been deemed on the one hand to require a more holistic approach that connects all different functions and university actors (Mcmillin and Dyball, 2009; Müller-Christ et al., 2014; Sammalisto et al., 2015) as well as universities with external organizations (Boni et al., 2015; Pérez-Foguet, 2008; Yarime et al., 2012) and communities (Dlouhá et al., 2013; Holm et al., 2015; Ramos et al., 2015). On the other hand, the scientific literature emphasises the persistence of multiple barriers that prevent SD from being properly integrated into higher education (Lozano, 2006; Velazquez et al., 2006). These barriers, which influence each other and change over time, have been summarized as: i) the lack of awareness; ii) the structure of higher education; and iii) the lack of resources for SD (Verhulst and Lambrechts, 2014).

These issues are particularly critical for engineering, a field that is especially relevant for addressing SD challenges. In fact, this discipline is characterised by approaches and methods mainly focused on technical paradigms and strong disciplinarity (Halbe et al., 2015). Consequently, both the promotion of cultural shifts to engineering academic structures and the practical integration of SD principles into curricula are particularly challenging (Mulder et al., 2012). For these reasons, limited responses have been made to the calls of curricula reform in engineering (Fenner et al., 2005; Lozano and Lozano, 2014; von Blottnitz et al., 2015), and much of the effort has been focused on developing individual courses on SD (von Blottnitz et al., 2015). Diverse approaches aimed at embedding SD in a more integrated and holistic way have focused specifically on technical universities through complementary strategies, such as: i) developing specific, integrated curricula that holistically connect engineering with SD (Lozano and Lozano, 2014); ii) promoting unconventional ways of faculty empowerment and engagement (Holmberg et al., 2008; Svanström et al., 2012); and iii) fostering innovative 
pedagogical approaches (Pérez-Foguet et al., 2017; Segalàs et al., 2010). Furthermore, other efforts have aimed at reinforcing the alignment between engineering and development studies (Boni and Pérez-Foguet, 2008; Pérez-Foguet, 2008; Pérez-Foguet et al., 2005), in line with a Sustainable Human Development (SHD) theoretical framework, focusing specifically on addressing global inequalities and the promotion of a more socially just world. (Absell, 2015). The concepts of SD and SHD do not have specific theoretical boundaries (ibidem). According to (Sen, 1999), an SHD approach defines development as a process of expansion of the capabilities and real freedoms that people enjoy. In this study, the concept of SHD is specifically used to highlight the fulfilment of basic needs and the expansion of human capabilities within SD approaches.

Human factors, such as the empowerment and the commitment of academics, have been recognised as critical issues for fostering organisational changes (Verhulst and Lambrechts, 2014). Accordingly, the importance of identifying and empowering committed academics, often heralded as sustainability champions, is central to overcoming resistance to fully engaging with SD and to promoting institutional changes towards sustainability (Lozano 2006; Ferrer-Balas et al. 2008). Furthermore, maximising the engagement of interested academics with little or no experience in SD is critical for fostering cultural changes in educational organisations. Indeed, integrating SD into academic activities requires a large effort and motivation, as changes are necessary not only in content but, above all, in methods (Segalàs et al., 2009), and as approaches go beyond disciplinarity (Barth and Rieckmann, 2012; Cebrián et al., 2015). For these reasons, HEI should motivate and incentivise the efforts aimed at integrating SD into the different functions of universities (Lozano et al., 2013b). Regrettably, the traditional disciplinary and rewarding structures too often leave these efforts unrewarded, such that it relies instead primarily on the individual commitment of a limited number of academics (Hoover and Harder, 2014; Krizek et al., 2012).

Additionally, conventional academic rewarding mechanisms, which are mostly characterised by a narrow disciplinary focus, represent major impediments to a more socially engaged higher educational system (Ferrer-Balas et al., 2008; Krizek et al., 2012). Commonly, these mechanisms discourage researchers from developing a proper outreach to non-academic stakeholders, which consequently hinders inter- and transdisciplinary collaborations, or the complex and integrated systems approaches required for addressing SD challenges (Stephens et al., 2008).

The effects of the conventional rewarding mechanisms are reinforced by current trends of globalisation of higher education, through which HEI have become inevitably part of competitive national and global networks, characterised by the increased relevance of rankings and benchmarking, which intensifies the attention on the productivity of universities (Morrissey, 2013). These trends emphasize primarily the research function of universities, which in turn underpin or accelerate changes related to the academic identity and work practices of academics (White, 2015). This increases the importance of the 'performance' of academics-specifically, the type of research they perform and the journals in which they publish (Hazelkorn, 2014). Thus, research productivity is an increasingly predominant part of the evaluation and promotion of academics, and the potential barriers and incentives related to this function that influence the willingness of academics to engage with SD should be better explored. However, during the literature analysis carried out for the present research, we did not identify scientific literature that specifically analysed the characteristics of scientific production of academics engaged in SD activities. Nonetheless, having a better understanding of this aspect is essential to replicate 
successful initiatives and to promote appropriate policies that lead academics to engage with SD.

In this context, this research addressed the open question of whether the research profiles of academics engaged with SD practices share any common patterns, using comparative analysis and characterisation of the scientific productivity of academic communities involved in activities related to SD. Specifically, two groups of academics with different degrees of expertise and involvement in SHD were compared and characterised, which highlighted common trends and similarities of their scientific production. The analysis focused on the scientific production of a community of academics involved in the activities of the European initiative 'Global Dimension in Engineering Education' (GDEE, 2014; Pérez-Foguet et al., 2017), aimed at promoting the integration of SHD as a crosscutting issue in teaching activities of technical universities.

\section{Research for SD}

Integration of SD into university research has remained, to some extent, underconsidered in the studies addressing sustainability in higher education, compared to other university functions (Hugé et al., 2016). This can be attributed to the fact that research for SD is difficult to define, due to different factors: i) the existence of different interpretations, and misconceptions, of the concept of SD (Filho, 2011, 2000); ii) the different use of the terms "sustainability" and "SD" among researchers, which has changed over time (Kajikawa, 2008); and iii) the diversity of stakeholders engaged with research in SD, bringing a multiplicity of perspectives and interpretations of research for SD (Hugé et al., 2016).

Different efforts have been made to define research for SD. Waas et al. (2010) define university research for SD as: "all research conducted within the institutional context of a university that contributes to sustainable development'. In order to avoid 'business as usual' research practices or even 'unsustainable research', the authors proposed the following sixteen characteristics of university research for $\mathrm{SD}$, which they argued should be compulsory: action-oriented; continuity; environmental; safety and security management; independence; knowledge transfer; local-global level of scale; local knowledge; multidimensionality; multi-/interdisciplinarity; participation; precautionary principle and uncertainty; public interest; short-, medium-, and long-term perspectives; societal peer review; sustainability impact; sustainability relevance; and transparency. In more recent research, other scholars conceptualise 'research for sustainability' with a set of characteristics including: multi-, inter-, and transdisciplinary research; coproduction of knowledge; normative and positive inputs; systemic integration; exploratory character; recognition of own limitations and assumptions; contextual knowledge; learningoriented perspective; production of socially robust knowledge; and attention to system innovation and transition (Hugé et al., 2016).

Bibliometric analyses have been useful for determining the principal domains of research for $\mathrm{SD}$, highlighting those disciplines and subdisciplines in which researchers predominantly focus their research efforts (Hassan et al., 2013; Quental and Lourenço, 2012; Xu and Marinova, 2013; Yarime et al., 2012). The status of research in sustainability science was analysed by Kajikawa et al. (2008) using a topological clustering method. The results highlighted fifteen main research domains: agriculture, fisheries, ecological economics, forestry (agroforestry), 
forestry (biodiversity), forestry (tropical rain forest), business, tourism, water, urban planning, rural sociology, energy, health, soil, and wildlife. Four main clusters are predominant among these domains: agriculture, fisheries, ecological economics, and forestry (agroforestry). Furthermore, the author combined the citation analysis with a natural language processing analysis, emphasising others common topics of research in sustainability science, such as education, biotechnology, medicine, livestock, climate change, welfare, and livelihood clusters (ibidem).

The landscape of the research for SD has changed in more recent years. In fact, the current scientific literature indicates that most of the previously separated domains have been integrated into larger domains that focus on the study of coupled systems, such as environmental systems, economy and business systems, fishery and forestry, energy systems, water resources, health, and urban and transport systems (Kajikawa et al., 2014). Other studies investigating the research strengths in SD highlight five main research clusters, emphasising the systemic focus of such domains: climate change, renewable energy, rural development, sustainable agriculture, and sustainable production and consumption (Hassan et al., 2013).

These changes in the research landscape reflect wider societal expectations and educational perspectives about SD that have also undergone changes in the last decades (Dlouhá et al., 2013) - specifically, from narrowly focused environmental issues to wider concerns related to global SD challenges. In addition, the acknowledgement that sustainability challenges require alternative ways of knowledge production and decision-making (Miller et al., 2014) has brought new imperatives for the research that addresses SD: on the one side, the need to focus on the linkage between various disciplines that range from biology to political and social sciences deepening dynamics and cross-systemic analyses (Waas et al., 2010); on the other side, the necessity of a new 'social contract' for research, in order to explicitly address scientific efforts towards the creation of a more sustainable future (Gibbons, 1999; Lubchenco, 1998). This implies not only a diverse and better knowledge communication (Dlouhá and Burandt, 2015) and outreach to the society at large, but also the active involvement of actors from outside academia in the research process (Lang et al., 2012; Max-Neef, 2005).

In this sense, a new conception of science and research for SD has emerged that transcends the boundaries of disciplines and academia; this is reflected in new fields of research, such as sustainability science (Clark and Dickson, 2003). This new approach acknowledges the complex interactions between human and natural systems and is value-based, problem-oriented, solutiondriven, and focused on knowledge co-production between science and society. It specifically acknowledges that research should be transformative - in other words, go beyond the description and analysis aspects that characterise traditional research (Heinrichs et al., 2016; Lang et al., 2012; Takeuchi and Komiyama, 2006). Compared to traditional disciplinary research, multi- and interdisciplinary research - which incorporate the combination of conceptual and methodological issues as well as diverse scientific disciplines - have greater potential to address sustainability challenges through specific research actions (Hugé et al., 2016; McCormick et al., 2016). Interdisciplinary research has been recognised as critical for addressing SD challenges (Lang et al., 2012), as well as an important driver towards more sustainable universities (Ferrer-Balas et al., 2008). However, transdisciplinarity - which refers to the involvement of non-academic actors in the research process - has the greatest potential to create relevant and robust knowledge that drives transformative actions forward (Binder et al., 2015; Gaziulusoy and Boyle, 2013; Lang et al., 2012; Max-Neef, 2005). Gaziulusoy and Boyle 
(2013) summarise the characteristics of the transdisciplinary research as: i) aiming to solve socially relevant and contextual problems; ii) based on evolving methodologies throughout the research; iii) requiring collaboration and coordination among different disciplines; iv) requiring participation or inclusion of the knowledge and perspective of non-scientific stakeholders in research; and v) normative, as it aims to transform the problem domain.

While transdisciplinary research has made substantial improvements in the broader understanding of the relevant complex problems related to SD and potential transformative solutions, progress on its integration into the research and educational functions of universities is limited (Miller et al., 2014). The scientific literature emphasises different barriers to integrating SD into HEI (Lozano, 2006; Lozano et al., 2013b; Velazquez et al., 2005), some of which are related specifically to research, such as: i) the conservative disciplinary structures and resistance to change by research; ii) the focus on short-term profit as a result of managerial thinking and policy making; and iii) the lack of appropriate qualitative and quantitative performance indicators (Verhulst and Lambrechts, 2014). In addition, the research function of universities is currently strongly conditioned by an increasing emergence of a corporate facet of universities, which some authors describe as an extension of the rationality of the market to the different academic functions (Boni and Gasper, 2012; Morrissey, 2013). In this context, the 'performance' and 'productivity' of academic practices have acquired growing relevance, to the extent that different scholars highlight a trend of 'commodification' and 'marketisation' of higher education (Locke, 2014; Tomlinson, 2015). Contextually, the globalisation agenda has constrained HEI from becoming part of competitive networks at national and global levels, with university rankings becoming increasingly more important for measuring universities global competitiveness.

Over the last years, university rankings have underpinned and accelerated changes of academic work practices, supporting the introduction of market-based salaries with merit or performance (Hazelkorn, 2014). Specifically, recruitment and promotion strategies have become increasingly reliant on ranking data, on the basis that these help to improve institutions' rankings. As a consequence, more weight has been given to the type of research that faculty undertakes and where it is published, prioritising international high-impact journals rather than other formats. Although there are various criticisms about ranking methodologies and their implications for the quality of education and research of HEI (Collins and Park, 2015), as well as sound proposals for alternative models that better fit the idea of sustainable universities (Boni and Gasper, 2012; Lukman et al., 2010), the increased relevance of rankings strongly influences strategic HEI decisions (Rauhvargers, 2014). Consequently, those universities willing to 'compete' in global rankings could, formally or informally, influence the academics to be aligned with the institutional goals. Examples of this include discontinuing research activities that negatively affect institutional performance, urging academics to increase their research output, quality, and citations in specific fields or disciplines, and rewarding faculty for publishing in highly cited journals (Hazelkorn, 2015). Consequently, unless universities have a clear institutional commitment to SD, these globalising and competitive trends can affect the proper integration of $\mathrm{SD}$ in research functions as well as other university functions.

\section{Research methods}


The research aim here was to compare and characterise the scientific production of a community of academics involved in activities related to the GDEE initiative (Pérez-Foguet et al., 2017).

The methods included the following steps:

1. Analysis of key international reference rankings and their data sources.

2. Sample selection within the GDEE community

3. Analysis of the research publications registered in the Scopus database.

4. Definition and operationalization of disciplinarity diversity indexes.

5. Generation of an overlaid journal map based on data downloaded from Scopus.

First, key international reference rankings and their data sources were analysed as current external drivers of university transformations. Second, two groups of academics were selected based on their role within the GDEE initiative and SHD expertise. Third, a bibliometric analysis of the research publications of the GDEE community using Scopus database were performed. The fourth step was focused on the definition and operationalization of two disciplinarity diversity indexes: i) the Shannon diversity index for the analysis of the degree of disciplinarity of individual researchers, and ii) the Rao-Sterling index for the analysis of portfolio of publications of the two groups. These two indexes, characterised by different level of complexity, provided complementary information. Finally, results were analysed using journal maps generated from the Scopus database. These maps can be interactively overlaid with journal distributions and used as a basic framework to project and visualize a specific dataset, such as portfolio assessment (Leydesdorff et al., 2015).

\subsection{Analysis of key international university rankings and their data sources}

Over the last decade, university rankings have become increasingly more important in measuring the global competitiveness of universities. The Academic Ranking of World Universities (ARWU, 2015) started in 2003 and is considered the most influential of university ranking systems; it was soon followed by others, such as the QS World University Rankings and the Times Higher Education World University Rankings, leading to the current proliferation of ranking systems.

The indicators of the top university rankings are linked to the main scientific databases. The Web of Science (WoS) and Scopus are, by far, the most frequently used databases by different scientific fields for literature searching purposes. Table 1 compares the number of journals covered by both databases. The Scopus database, introduced by Elsevier Science in 2004, is the largest searchable citation and abstract source of scientific literature. WoS, provided by Thomson Reuters, includes the largest historical citation trackbacks (1990 to present) and a unique search method, using cited reference searching. It includes the Science Citation IndexExpanded database (SCI-E), with over 8,500 major journals across 150 disciplines, and the Social Science Citation Index database (SSCI), with over 3,000 journals across 55 social science disciplines (see http://wokinfo.com). Both databases are commonly used for calculating the impact factor of scientific journals, through the Journal Citation Report. WoS also includes the Essential Science Indicators (ESI), available as a 10-year rolling file with slightly over 6,500 journals from SCI-E/SSCI, which cover emerging science trends as well as influential researchers and institutions in different fields of research. 


\begin{tabular}{l|l|l|l} 
& Overlap Titles & Unique Titles & Total Titles \\
\hline Scopus & 11377 & 8432 & 19809 \\
\hline Web of Science & 11377 & 934 & 12311 \\
\hline
\end{tabular}

Table 1. Coverage of the Scopus and WoS databases. Titles of journals, books, and proceedings. Source: http://adat.crl.edu (September 2015).

Scopus classifies journals into 27 subjects, which in turn are clustered into four main subject areas: health, life, physical science, and social science. The category 'multidisciplinarity' is considered a subject itself but is used only for a reduced number of journals. Both specialized and general journals can be classified in more than one subject. For this reason, a total of around $30 \%$ of the records are estimated to be duplicated in Scopus (that is, journals classified into two or more subjects of Scopus) (Chadegani et al., 2013). Conversely, the ESI classifies journals in only one of its 22 subjects.

In the ranking systems, universities are mostly evaluated with a limited number of scientific domains that rely on main scientific databases. For instance, indicators of the ARWU related to scientific publications in the field of engineering/technology and computer science (ENG) only consider the articles indexed in specific engineering-related fields of the SCI-E/SSCI and the articles of the highly cited authors of engineering-related ESI fields. Consequently, and especially in technical universities, institutional policies could discourage those research initiatives that are not aligned with the specific engineering fields of the main scientific databases, by not providing appropriate incentives or visibility. As a result, the described trends represent potential barriers to the research production based on knowledge areas that are still perceived to be 'peripheral' with regard to traditional core engineering research areas, such as $\mathrm{SD}$. One specific contribution of this research is the analysis of the scientific publications of the sample using the ARWU categories, after a conversion of bibliometric data from Scopus.

\subsection{Sample selection}

More than three hundreds academics, mostly lecturers in the field of engineering from different European technical universities, were involved in diverse activities of the GDEE project, such as: i) elaboration of training materials; ii) coordination and evaluation of online courses addressed to academics; and iii) attendance of courses. A detailed description of these activities can be found elsewhere (Pérez-Foguet et al., 2017). With respect to this research, it is worth mentioning that almost one hundred contributors, mostly academics, closely collaborated to develop training materials and teaching resources and to give, coordinate, and evaluate online courses. In addition, more than two hundred academics, interested in receiving trained in SHD, participated in one or more GDEE online courses offered in three European countries.

For the purpose of this study, two groups of the GDEE community, with different degrees of expertise and involvement in SHD, were selected to analyse their scientific production. The first group contained 43 'contributor' experts in SHD issues, who are authors of the GDEE training materials, including both theoretical (GDEE, 2014) and practical (GDEE, 2015) resources that were used to developed the nine online training courses addressed to engineering academics. The contributor group comprised mostly academics and researchers in the field of engineering, 
who were selected from 16 universities from five European countries (Ireland, Italy, Spain, Sweden, and United Kingdom) based on their expertise in specific SHD issues. (Note that professionals involved in global learning issues and NGOs practitioners also collaborated on the development of different materials and courses).

The second group contained 47 'participants' in the GDEE training initiative, who completed one or more online courses offered through the Spanish learning platform. The course structure consisted of nine online short courses, each lasting approximately three weeks. All registered participants could access materials and activities without completing the course. For this research, only those participants who completed all activities to satisfy the courses' criteria for earning a certificate were selected. These were mostly lecturers and engineering $\mathrm{PhD}$ students, from fifteen Spanish, two Portuguese, and one Swedish university, who were interested in acquiring SHD competences.

Fig. 1 presents the percentage of the professional categories of the sample for the participant group (left) and the contributor group (right). The category 'other' comprises professionals in training of entities and NGOs related to global learning issues.

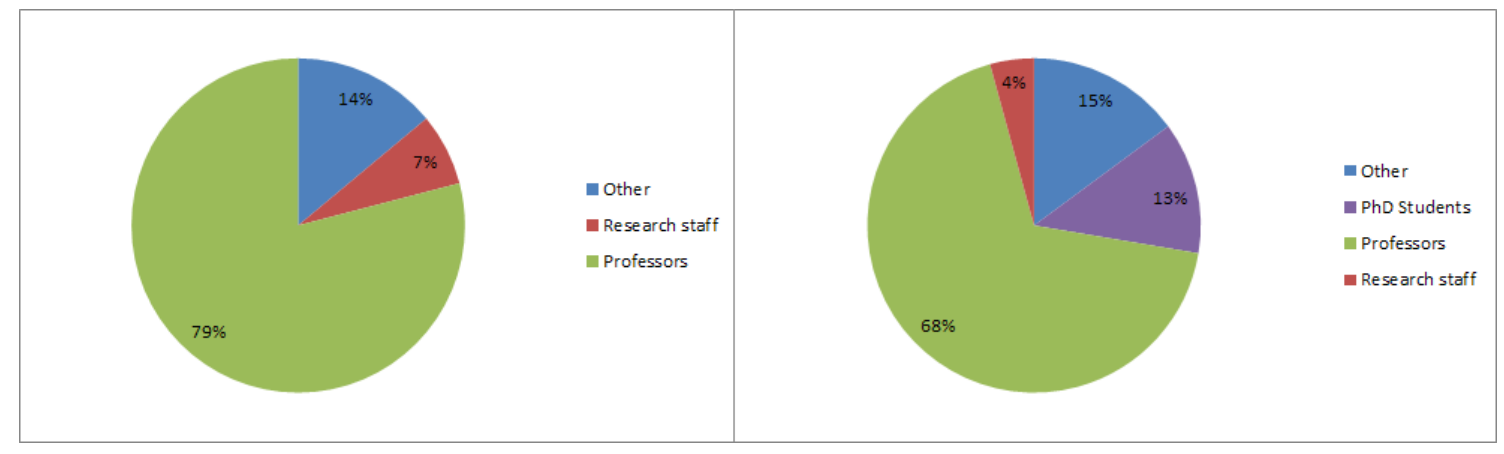

Figure 1. Professional categories of the groups of participants (left) and contributors (right).

Our research included: i) a bibliometric analysis of the scientific publications of the two groups, and ii) a characterization of common trends and similarities of the scientific productivity of these collectives, following the insight of previous research (Hassan et al., 2013).

\subsection{Analysis of the research publications of the GDEE community registered in the Scopus database}

All information needed to select publications for each researcher, including the full name, university affiliation, and address, were available to the authors. As the analysis focused specifically on the scientific publications of a selected number of known authors, no advanced searching/analytic features were needed. For this reason, two main characteristics were prioritised for selecting the database for conducting the analysis: i) availability of accurate and comprehensive information on the scientific publications of the targeted researchers, to minimise possible author ambiguity issues; and ii) inclusion of a broad range of journals and publications for each researcher, in order to characterise researchers profiles taking into account the highest number of scientific contributions. 
Three scientific databases, namely Google Scholar, Scopus, and WoS, were initially taken into consideration prior to conducting the analysis. As the Google Scholar interface was found to be not particularly suitable, the authors excluded the possibility of using software interfaces to analyse specific Google metrics. Consequently, only Scopus and WoS were evaluated. After examining the most recent scientific literature comparing the two different databases (Lasda Bergman, 2012; Minasny et al., 2013; Roales-Nieto and O’Neill, 2012; Torres-Salinas et al., 2009; Vieira and Gomes, 2009), different trials were conducted by selecting the publications of specific authors using Scopus and WoS. The Scopus searching feature 'Author Identifier' matching author names according to their affiliation, source title, subject area(s), and coauthor(s) - was found to be accurate and more rapid than the WoS feature 'Distinct Author Sets'. Contextually, a higher number of publications were included after performing author searches with Scopus than with WoS, confirming previous studies comparing the two databases (Abrizah et al., 2013; Chadegani et al., 2013; Harzing and Alakangas, 2016). This characteristic of Scopus was found particularly appropriate for analysing the GDEE community, which comprised a number of young academics and $\mathrm{PhD}$ students, with a number of publications in lower-impact journals. Further, as Scopus does not have complete references prior to 1996, it was not an obstacle for the purpose of this research. Thus, after comparing the two databases, Scopus was deemed to be better suitable overall than WoS for analysing the publications of the two groups.

Nonetheless, WoS presents some advantages for analysing the results using ARWU fields. In fact, the ARWU fields are based on the five categories of the ESI classification (with the exception of multidisciplinarity): natural sciences and mathematics (SCI); engineering/technology and computer sciences (ENG); life and agriculture sciences (LIFE); clinical medicine and pharmacy (MED); and social sciences (SOC). Journal articles classified under the category 'multidisciplinarity' were clustered into one of the five ARWU fields on a per-paper basis.

The various journal-level taxonomies applied by scientific databases hampered a clear correspondence between the different database classifications. Although sound alternative classifications have been proposed (Science-Metrix, 2016), no single classification scheme has been widely adopted by the international bibliometric community to date. In order to analyse data gathered from Scopus through the ARWU categories, the authors developed a table of correspondences among Scopus Subject areas, including their subclassifications, the five ARWU fields, and the corresponding ESI categories (Table 2). Note that the Scopus area of physical sciences was split in SCI and ENG fields in the ARWU. Further inconsistencies, which are indicated in the table with an asterisk, included: i) the category of arts and humanities is not considered in the ARWU indicators; ii) psychology is not considered in the ARWU for the indicator of highly-cited researchers; and iii) the ESI category 'social sciences, general' is split and assigned on a paper-by-paper basis into the SOC or MED field of the ARWU (see website for an exhaustive description of the ARWU fields; ARWU, 2015). It is worth highlighting that, due to the relatively low number of documents examined in this research, all the unclear or doubtful cases that had the inconsistencies highlighted above were assessed on an individual basis. 


\begin{tabular}{|c|c|c|c|}
\hline Scopus Subject Area & Scopus Subject Area Classific. & ARWU-FIELD & ESI subjects \\
\hline Physical Sciences & Earth and Planetary Sciences & $\mathrm{SCl}$ & Geosciences \\
\hline Physical Sciences & Chemistry & $\mathrm{SCl}$ & Chemistry \\
\hline Physical Sciences & Mathematics & $\mathrm{SCl}$ & Mathematics \\
\hline Physical Sciences & Physics and Astronomy & $\mathrm{SCl}$ & Physics \\
\hline Physical Sciences & & $\mathrm{SCl}$ & Space Sciences \\
\hline Physical Sciences & Engineering & ENG & Engineering \\
\hline Physical Sciences & Chemical Engineering & ENG & \\
\hline Physical Sciences & Energy & ENG & \\
\hline Physical Sciences & Materials Science & ENG & Materials Science \\
\hline Physical Sciences & Computer Science & ENG & Computer Science \\
\hline Physical Sciences & Environmental Science & LIFE & Ecology/Environment \\
\hline Life Sciences & Agricultural and Biological Sc. & LIFE & Agricultural Sciences \\
\hline Life Sciences & & LIFE & Plant \& Animal Science \\
\hline Life Sciences & Bioch., Genetics and Mol. Biology & LIFE & Biology \& Biochemistry \\
\hline Life Sciences & & LIFE & Molecular Biology \& Genetics \\
\hline Life Sciences & Immunology and Microbiology & LIFE & Immunology \\
\hline Life Sciences & & LIFE & Microbiology \\
\hline Life Sciences & Neuroscience & LIFE & Neuroscience \\
\hline Life Sciences & Pharmacol., Tox. and Pharmceu. & MED & Pharmacology \\
\hline Health Sciences & Medicine & MED & Clinical Medicine \\
\hline Health Sciences & Health Professions & MED & Social Sciences, General * \\
\hline Health Sciences & Nursing & MED & \\
\hline Health Sciences & Dentistry & MED & \\
\hline Health Sciences & Veterinary & MED & \\
\hline Social Sciences & Psychology & MED * & Psychiatry/Psychology \\
\hline Social Sciences & Social Sciences & SOC & Social Sciences, General * \\
\hline Social Sciences & Business, Manag. and Accounting & SOC & Economics/Business \\
\hline Social Sciences & Econ., Econometrics and Finance & SOC & \\
\hline Social Sciences & Decision Sciences & $\mathrm{SOC}$ & \\
\hline Social Sciences & Arts and Humanities & $\mathrm{SOC}^{*}$ & \\
\hline (all 4) & Multidisciplinary & (all 5) & Multidisciplinary \\
\hline
\end{tabular}

Table 2. Correspondence between subjects and categories of Scopus and WoS databases.

An author search was performed in the Scopus database for each member of the contributor and the participant groups, for a total of 90 authors, by entering each author's last and first names and affiliation. Data was collected in September 2015, one year after completion of the GDEE courses (Pérez-Foguet et al., 2017). Only about $60 \%$ of the members of the GDEE community had a Scopus ID (31 contributors and 22 participants). The lack of an ID corresponds, among contributors, to NGO practitioners and other SD experts with no research publications and, among courses participants, mainly to academics, as well as a few practitioners and $\mathrm{PhD}$ students.

After examining the scientific literature of all members of the GDEE community with a Scopus ID, specific data were gathered for each member: the number of journal articles and the number of total contributions, the year of the first contribution registered in Scopus, the h-index, and the number of counts in the different categories of classification for each journal. In Scopus, all journals can be classified in one or more areas, so that the number of counts in each category can be equal to, or higher than, the number of contributions. Finally, all data were organised in spreadsheets to facilitate a deeper analysis.

\subsection{Definition and operationalization of Disciplinarity Diversity Indexes}

Stirling (2007) outlines a heuristic of 'diversity' in science. Accordingly, the diversity can be generally defined as an 'attribute of a system whose elements may be apportioned into categories' (ibidem). Different attributes of the diversity of scientific production can be taken into account for its measurement: i) variety (the number of distinctive categories); ii) balance (the evenness of the distribution); and iii) disparity (the degree to which the categories differ 
from each other) (Stirling, 2007). The degree of diversity of researcher production can be measured according to these different attributes through specific indicators, such as Shannon, Herfindhal, Gini, or Rao-Stirling indexes, which have been extensively described elsewhere (Leydesdorff and Rafols, 2011; Porter and Rafols, 2009).

The scientific literature discusses and analyses multiple concepts of disciplinarity in its different variant (multi-, inter-, and transdisciplinarity) (see Wagner et al., 2011, p. 16), some of which focused specifically on sustainability (Binder et al., 2015; Gaziulusoy and Boyle, 2013; McCormick et al., 2016). From a bibliometric perspective, a lack of consensus on the concept of disciplinarity and its measurement is noteworthy (Sanz-Menéndez et al., 2001), as it specifically implies differences in quantitative measurement and a lack of agreement on pertinent indicators aimed at measuring its different variants. Additionally, bibliometric literature explicitly indicates that the term interdisciplinarity has been cause of conflicting meaning. Indeed, Rafols and Meyer (2009) report that the concept of interdisciplinarity is 'problematic, if not controversial', and that it is not the most appropriate term to explain the cognitive dynamics at the boundaries of disciplines. The American National Academies (National Academies, 2004) identifies the process of integrating different bodies of knowledge as 'interdisciplinary research' (IDR), which includes all variants of disciplinarity (multi-, inter-, and trans-). Accordingly, in this research, the measurement of 'interdisciplinarity' refers to IDR including all variants of cross-disciplinary research, following Wagner et al. (2011).

Different approaches for diversity can be applied to compare the interdisciplinarity of researchers of university units: i) diversity of references (Sanz-Menéndez et al., 2001); ii) diversity of citations (van Leeuwen and Tijssen, 2000); and iii) diversity of publications (Carayol and Nguyen Thi, 2005). Due to the characteristic of this research, the latter approach in defining disciplinarity has been selected. Thus, disciplinarity is measured in terms of the spread of researcher's publications over different scientific domains, according to the journal classification in the main scientific databases.

Two different indexes of disciplinarity diversity are used, respectively: i) the Shannon diversity index, for the analysis of the degree of interdisciplinarity of individual researchers; and ii) the Rao-Sterling index, for the analysis of portfolio of publications of the two groups. These two indexes, described extensively by Leydesdorff and Rafols (2011), are characterised by a different level of complexity and, in this research, provided complementary data. On the one side, the Shannon index reflects how many different types of journals - according to a specified classification of disciplines or categories - exist in a specific dataset (variety) and, simultaneously, how these journals are distributed in a given classification (evenness). Higher values of the index indicate a more diverse set of publications, whilst values close to zero indicate that a researcher's publications fall into a lower number of disciplines. Hereinafter, the Shannon diversity index is expressed in relative terms with respect to the highest possible value given a specific number of categories. The values of the relative index fall between 0 and 1 . On the other side, the Rao-Stirling index captures not only the variety and the evenness of researchers' publications in different disciplines (similar to the Shannon index) but also the degree of 'disparity' of such disciplines - that is, the difference of these disciplines among themselves, taking into account the ecological distance between different subsets of journals. Whilst the Shannon index can be easily computed for each researcher using a set of publication data downloaded from a scientific database, the Rao-Sterling index relies on a specific metric of distances between the various disciplines, provided by science maps (Rafols and Meyer, 2009). In contrast to the Shannon index, the Rao-Stirling index has no absolute reference values. 
Consequently, the value of this interdisciplinarity index is meaningful only when is compared to similar cases, for example by comparing the portfolios of publications from different research groups (Leydesdorff et al., 2015). Accordingly, this study specifically compared the two groups of the GDEE community analysed, respectively contributors and participants.

\subsection{Generation of an overlaid journal map based on data download from Scopus}

Bibliometric analysis can be greatly enriched with the help of appropriate visualisations. Science maps are suitable tools for this purpose, being visual representations built on the overall science interrelationship based on journal articles (Boyack et al., 2005; Leydesdorff et al., 2015; Rafols and Meyer, 2009) Science maps allow to visually identify major areas of science and their sizes, similarities, and interconnectedness. In fact, similar to cartographic maps, they provide a broad view of the whole scientific landscape, representing a base upon which particular research cases can be situated and intuitively analysed. They are particularly helpful as they allow different aspects of disciplinarity to be analysed, such as: i) variety (e.g., the number of disciplines); ii) balance (e.g., the distribution of the disciplines, expressed by the relative size of nodes in the map); and iii) disparity (the degree of difference among the disciplines, expressed by the distance between the nodes of the map) (Porter and Rafols, 2009).

Given the purpose of this study, the base map tool called 'Overlay.exe for data from Scopus' (Leydesdorff et al., 2015) was selected, This is a global map of science that can be interactively overlaid on journal distributions in sets downloaded from Scopus. Any set of publication downloaded from Scopus can be projected onto a base map by displaying specific mapping information. Subsequently, the portfolio of documents can be assessed in terms of the spread across journals and journal categories. Furthermore, base maps can be used as distance metrics for measuring interdisciplinarity in term of journal composition, using the Rao-Stirling diversity index (Leydesdorff et al., 2015).

\subsection{Limitations of the study}

The limitations of this study are mainly related to the sample involved in the analysis and the methodology applied.

A reduced sample size implies lower precision of estimates. This study, however, highlights the main differences between two groups of data, rather than focusing on a detailed comparison of similar characteristics of both groups. Thus, it can be consider that the reduced sample size did not affect main conclusions reached. Another limitation is related to origin of the sample, the GDEE initiative, integrated almost exclusively by academics related to European institutions, and specifically with interest in SHD initiatives. Further analyses including a broader community of researchers, from both origin and SD perspectives, would reinforce these preliminary results

With respect to the methodology, it can be argued on the one hand that the characterisation of the community could be more accurate if it included qualitative information, in addition to research production. As this regards, in a recent work, Lazzarini et al. (under revision) complement the present analysis by including a survey addressed to all academics within the cohort with information about their research, teaching activities, and social outreach activities. 
The improved understanding of the GDEE community did not modify results obtained here, but helps to define further strategies of SD promotion. On the other hand, comparing data provided by Scopus with the WoS database could have provided additional insight. This would be encouraged for further analyses involving larger communities; in the case analysed here, an initial screening of the WoS database showed a severe reduction in the research footprint of the community. Finally, the analysis of other university rankings could be also explored in order to find evidence to confirm the findings of this study.

\section{Results}

Table 3 summarizes the overall results of the analysis of the two groups. It is worth highlighting some differences between GDEE contributors and participants. First, the contributors presented a higher number of research profiles in Scopus (ID) than the participants. Nonetheless, the participants with Scopus ID were scientifically more productive, with 16.5 papers/person instead of 7 of contributors. Second, the research publications of the contributors, with both articles and total contributions considered, were more concentrated in the category of engineering than those of participants. Finally, the contributor articles showed a higher degree of disciplinary diversity, with an average of 2.63 categories, versus 1.98 for the participants. Equivalent results were found when considering total contributions, with 2.53 and 1.87 categories for contributors and participants, respectively.

\begin{tabular}{|c|c|c|c|c|c|c|c|c|c|c|}
\hline & ID & No ID & Np & Nt & Eng/Np & Eng/Nt & Ncat & Ncat/Np & Ntca & Ntca/Nt \\
\hline Contributors & 31 & 12 & 220 & 352 & $60 \%$ & $64 \%$ & 578 & 2.63 & 891 & 2.53 \\
\hline Participants & 22 & 25 & 362 & 536 & $36 \%$ & $42 \%$ & 715 & 1.98 & 1003 & 1.87 \\
\hline Total & 53 & 37 & 582 & 888 & $45 \%$ & $51 \%$ & 1293 & 2.22 & 1894 & 2.13 \\
\hline
\end{tabular}

Table 3. Summary of the main characteristics of both analysed groups. From left to right: number of people with or without a Scopus ID, number of papers (Np), number of total contributions (Nt), percentage of contributions in engineering subjects, total number of hits in different categories (Ncat), ratio of Ncat over Np, number of hits of total contributions (Ntca), and ratio of Ntca over Nt.

Fig. 2 presents the total number of scientific contributions of the whole sample analysed, which comprises all members of the two groups, according to Scopus classifications. It can be appreciated that, in coherence with the target of the project, the average profile of the academics of the GDEE community has the most relevant activity in the field of engineering, followed by environmental science and chemical engineering. 


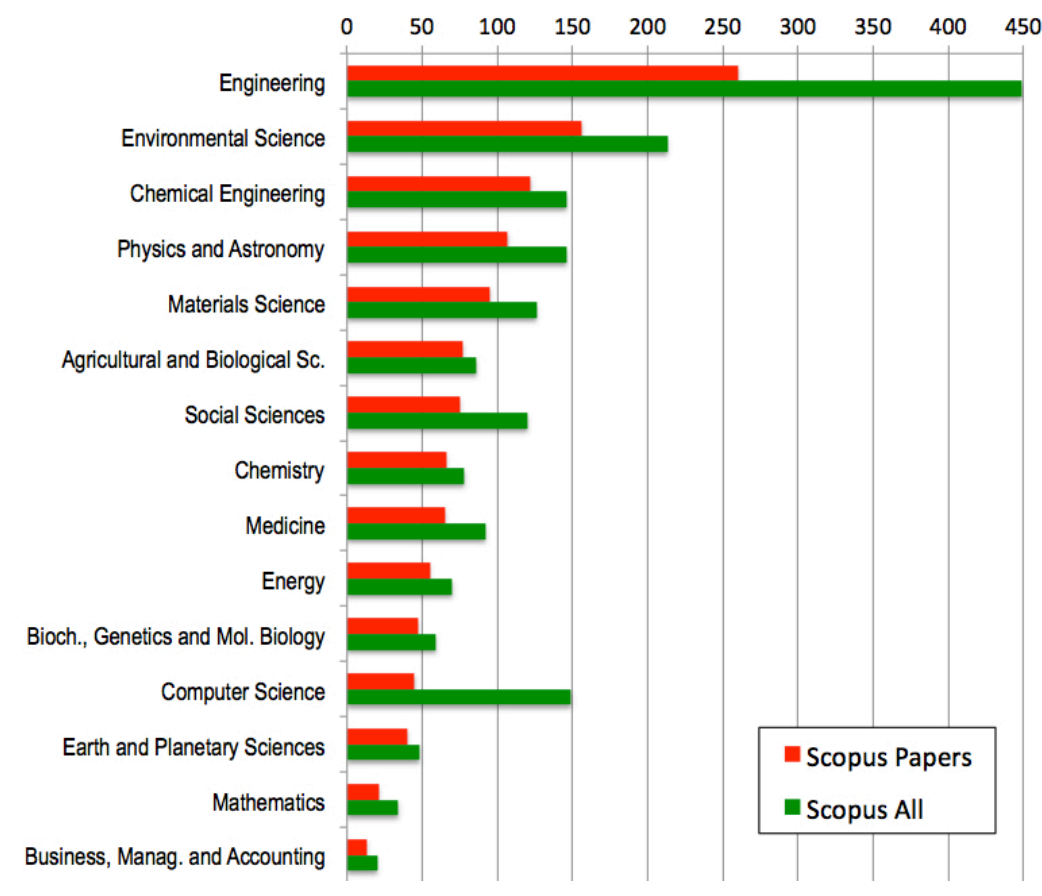

Figure 2. Number of scientific contributions by Scopus categories of the whole sample analysed (only the categories with more than 10 contributions are displayed). Scientific articles are displayed in red. All researchers' contributions (including articles, conference papers, and book chapters) are displayed in green.

Fig. 3 presents the relative distribution of the scientific publications, papers, and all contributions for the two groups. Engineering was the predominant subject in all four cases; thus, it was set as the reference value of $100 \%$ for all. Subjects were ordered by decreasing the relative value of articles of contributors. The highest values for the contributor group are in environmental science and social sciences, while the participant group had higher relevance in more categories (such as physics and astronomy, material science, agricultural and biological sciences, and medicine). The relative behaviour of the metrics of the two categories of 'journal articles' and 'all contributions' can be considered equivalent, except for the subject of computer science. Remarkably, the key areas that differentiate between the two groups are social science and medicine. In both cases, a particularly relevant research activity of one group in one field is contrasted to a significantly lower activity in the other. 


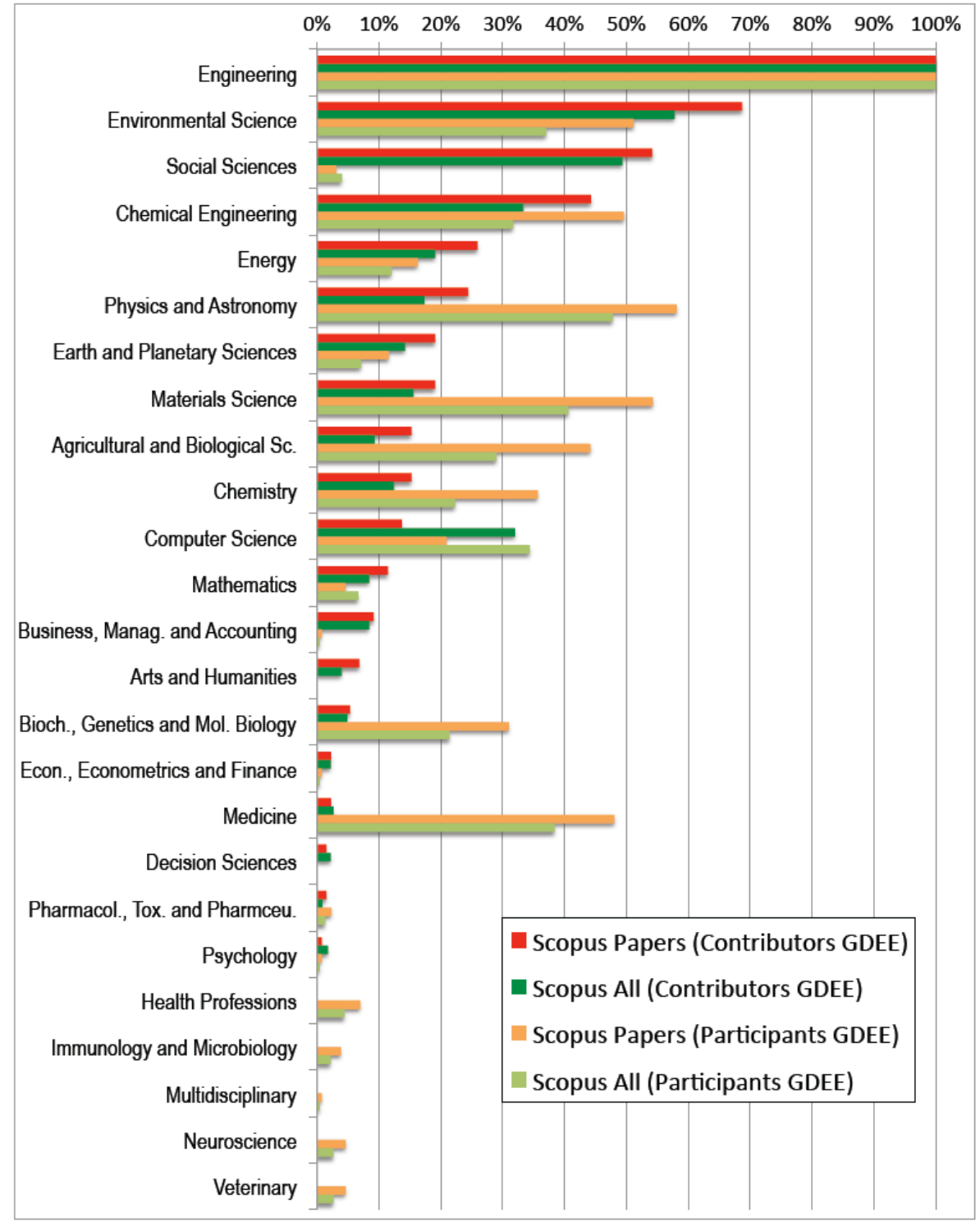

Figure 3. Relative distribution of Scopus subjects in the four sets of data: journal articles of contributors (red), all contributions of contributors (green), journal articles of participants (orange), and all contributions of participants (pale green).

Fig. 4 presents the number of articles (left) and all contributions (right) of both groups classified according to ARWU fields. After a conversion of data provided by Scopus, the total number of contributions is displayed, rather than the relative percentages shown in Fig. 3. It is worth noting that the influence of potential inconsistencies in correspondences indicated in Table 2 are not relevant since any unclear or doubtful cases were assessed on a per-paper basis. The four groups appear similar at first, except for scaling. With aggregated data, however, it is clearer that the participant group was scientifically more productive than the contributor group in each area except for social sciences. Further, Fig. 4 clearly summarizes the main difference between both groups: namely, the scientific productivity in the categories of medicine and social sciences. 


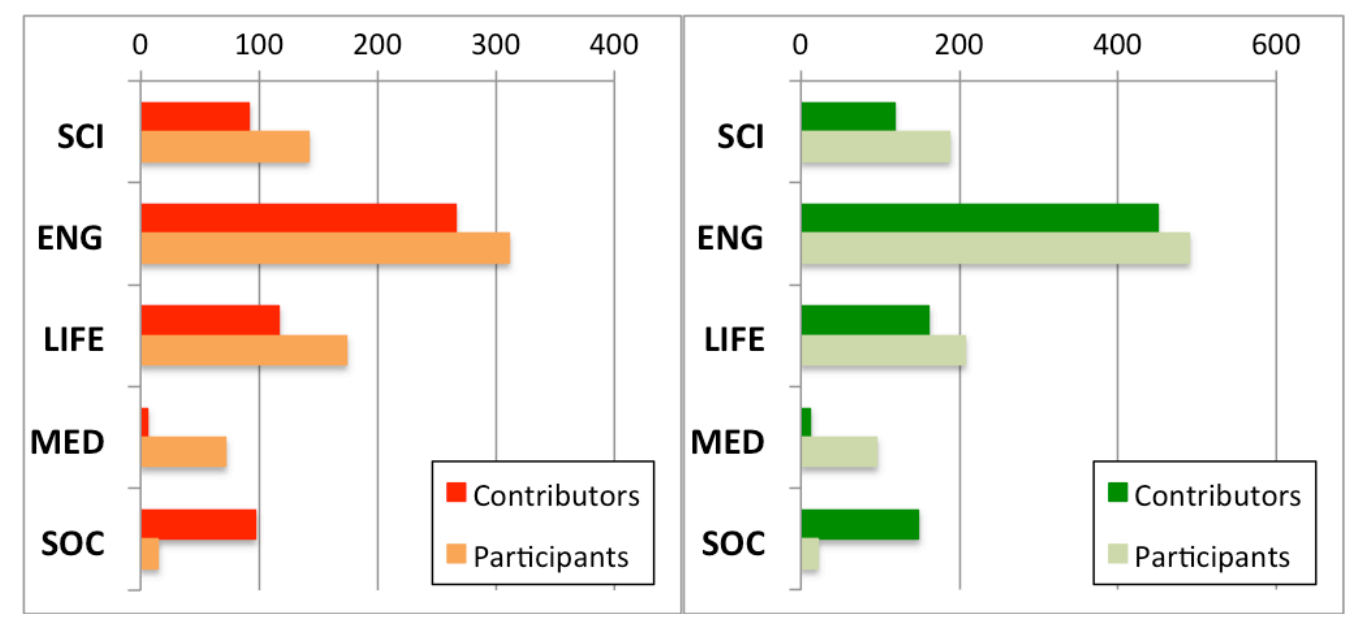

Figure 4. Number of journal articles (left) and all contributions (right) in Scopus, by GDEE contributors and participants, classified by ARWU fields.

Fig. 5 shows disaggregated data of the number of articles published and the year of the first contribution registered in Scopus of three groups: participants (red circle), contributors (pale blue triangle) and contributors with more than five publications in social science (blue triangle). The decision to display contributors active in social science in a separate series responded to the need to analyse the distribution of the researchers with publications in significantly diverse areas of science, such as engineering and social science. Fig. 5 shows that all levels, from junior to more consolidated profiles, were evenly represented among the three groups analysed. No top scientists, that is, with more than one hundred articles, were represented in the collective examined. Remarkably, there was no polarisation - meaning, a clear distinction into two completely opposing groups - in the distribution of the groups of participants and contributors. Similarly, the researchers of the contributor group who were 'active in social sciences' were evenly distributed throughout the whole chart, with no dependence relationship with either timing or volume of publications.

Three subgroups of junior to more consolidated researchers, with different research profiles, were well identifiable. It is worth noting that two-thirds of participants were active in Scopus before year 2005, roughly one third of whom had a higher research profile of more than 30 articles. Focusing on participants, it is notable that people with diverse profiles were interested in being trained in SD. A more junior profile can be noted in the lower-right quadrant (e.g., those with less than 10 publications and a first contribution in 2007 or later). The lower-left quadrant shows academics who started their activity before 2005 but most likely did not follow it (possibly focusing on teaching). Finally, the upper-left quadrant shows a group of consolidated researchers. 


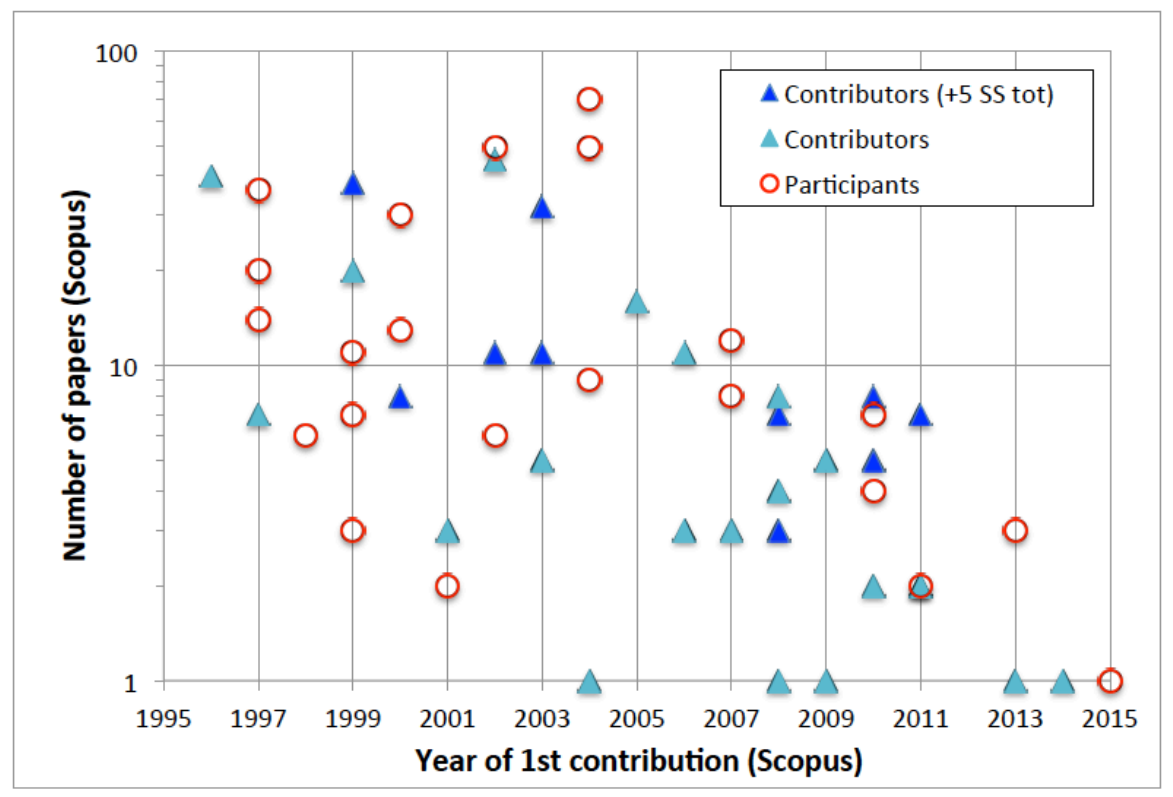

Figure 5. Number of journal articles in Scopus compared to year of first contribution, disaggregated by three different groups: contributors with more than five publications in social sciences (blue triangle), contributors (pale blue triangle), and participants (red circle).

Fig. 6 presents the number of total contributions in Scopus related to the Shannon Index. The index is expressed in relative terms, with respect to the value of a completely uniform distribution between the 27 categories. The value of the index for each researcher depends on the percentage of his/her contributions in each one of the different Scopus categories in which the journals are classified. The spread of subgroups was similar to that previously analysed. The cases with few contributions to a single subject were easily identified in the lower-left quadrant. The highest value of the Shannon index corresponds to a contributor with 53 publications in 12 subjects, quite uniformly. Note that the relative index value multiplied by 27 is 11.5 . The second highest value of the relative Shannon index, 37.9\%, corresponds to a participant with 14 publications in total, distributed also uniformly and in 12 categories. The maximum number of categories to which a single academic has contributed is 15 (specifically, this was by a contributor with an index value of $25.4 \%$ ).

Medium-to-high scientific productivity was not related to the interdisciplinarity of research and, again, there was no polarisation between the two groups. Additionally, neither the volume nor the disciplinarity of the research characterize the contributors with scientific production in social sciences.

The majority of the researchers of the two analysed groups had a Shannon index score between $9 \%$ and $17 \%$, which roughly corresponded to 2 to 4 Scopus subject areas. It could be argued that research productivity of the majority of the community was not very diverse. Nonetheless, it is worth stressing that the diversity expressed with these data was related to the number of disciplines in which the different researchers are active (the degree of variety), according to Scopus classification. No information was provided on the degree of difference among disciplines (disparity). 


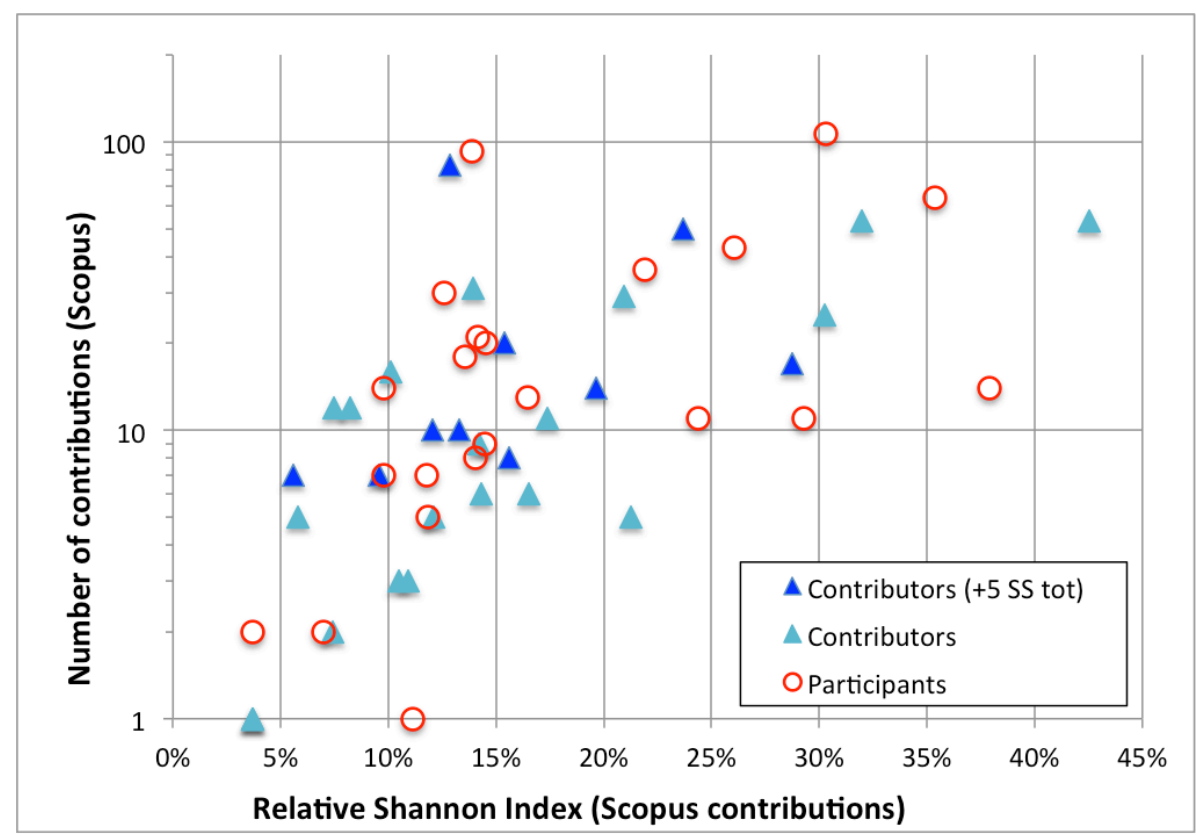

Figure 6. Number of total contributions in Scopus compared to Relative Shannon Index, disaggregated by three different groups: contributors with more than five publications in social sciences (blue triangle), contributors (pale blue triangle), and participants (red circle).

Figs. 7 and 8 show the journals distribution of the scientific production of the groups of contributors and participants, respectively, highlighted onto a base map of global science (in pale green), according to Scopus classification. The visualisation, with the help of overlaid Science Maps, significantly improves the data provided by the indicators. Journals of engineering fields were well visible at the top of the two maps (blue and yellow), as these were predominant subjects of research for both groups. Thereafter, the contributors and the participants showed an opposing journal distribution, with journal categories related to social sciences journals (shown on the left) represented more by contributors (Fig. 7), and categories related to medicine, biotechnology, and medical physics (shown on the right) represented more by participants (Fig. 8). 


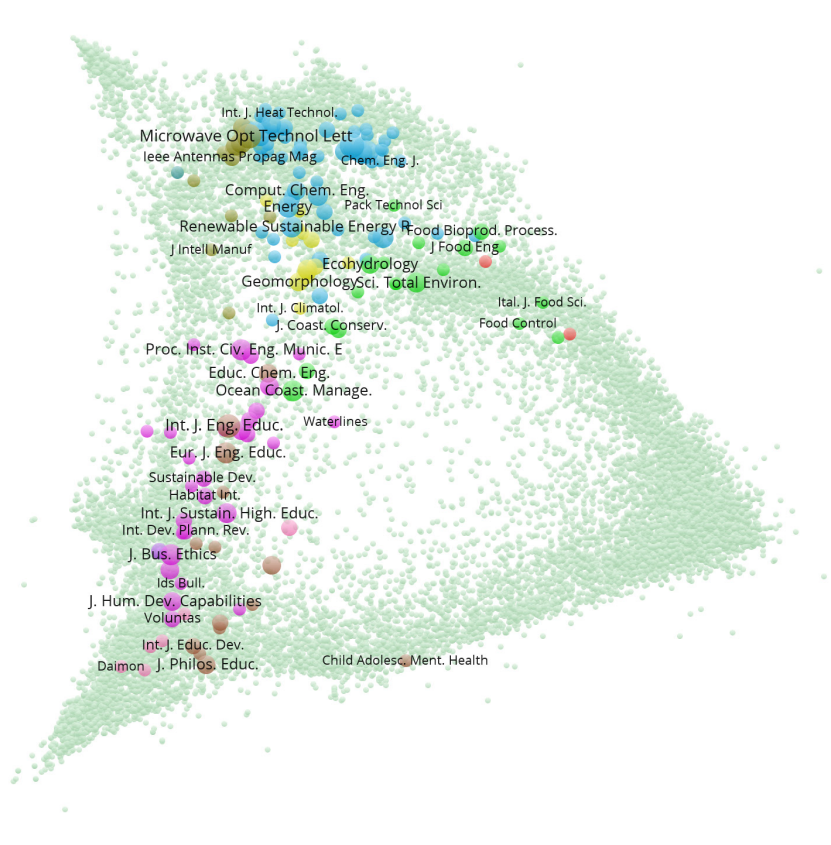

\& vosviewer

Figure 7. Journal distribution of the scientific output of the group of 'contributors'.

\& VOSviewer

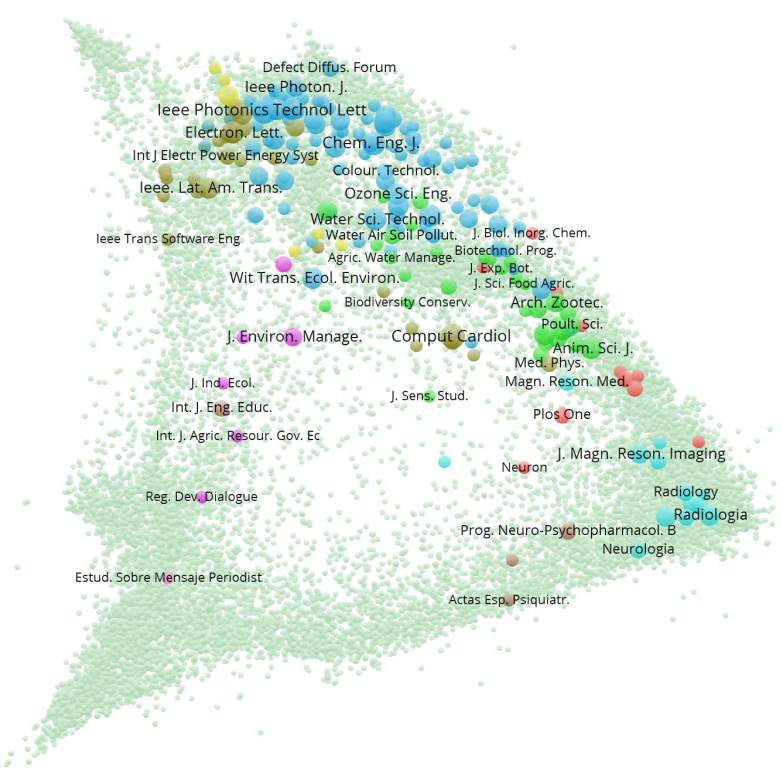

Figure 8. Journals distribution of the scientific output of the group of participants.

As outlined earlier, the visualisation provided by science maps was particularly useful to assess the interdisciplinarity of the different portfolios of publications of the two groups analysed. In addition, the Rao-Sterling interdisciplinary index can be operationalized using the metrics of the distance among the respective subsets of journals provided by the map. The calculation of the Rao-Sterling index showed that the degree of interdisciplinarity of the two groups was similar. 
In fact, the index was almost identical for the two groups, with 0.1848 for contributors and 0.1892 for participants. It can be visually appreciated that, although the two groups spread across the map in opposite directions, the relative distances between core engineering publications and other publications classified in different disciplines was similar.

\section{Discussion}

This research presented a comparative analysis and characterization of the scientific production of a community of academics involved in training activities aimed at facilitating the integration of SHD in academic practices. Specifically, two groups of academics with different degree of expertise and involvement in SHD were compared: a group of experts in SHD with a group of academics participating in training courses on SHD in the framework of the European initiative GDEE.

As mentioned above, the methods focused on bibliometric analysis, with specific attention paid to the role of university rankings as current external drivers of university transformations that potentially can negatively affect the integration of SD in university functions. Accordingly, data gathered from the Scopus database were analysed not only using Scopus categories, but also using the fields of one of the most influential ranking systems, the ARWU. The methodology was tested with a group of 90 people, the great majority of whom are academics.

The community analysed covered a wide spectra of academics, from junior to more consolidated research profiles. Unexpectedly, the analysis revealed that a high percentage of academics involved in the training initiative had no Scopus ID. Thus, it was assumed that they have had no scientific contributions in international conferences or indexed journals. This could be due to focusing their academic activity specifically on teaching and/or disseminating their research mostly at local level.

The main findings show that the academics of the two groups presented a scientific production specifically focused in engineering-related disciplines, in line with the sample analysed. Notwithstanding, their research extends to other disciplines, and the analysis indicates a significant difference between the two groups. After comparing the respective portfolios of publications, the main difference is that contributors showed relevant research activity in the disciplines related to social science, while participants were significantly active in health science disciplines. The relative concentrations of publications, which can be appreciated through overlaid science maps, shows that the distribution of publications from participants in the medicine disciplinary area of the map are mainly focused in disciplines somehow related to engineering, such as biotechnology, medical physics, magnetic resonance, and radiology. These results partially confirm previous bibliometric studies that highlight common topics of research in sustainability science related to engineering, medicine, and social sciences, of energy and urban planning, biotechnology and medical, and welfare and livelihood, respectively (Kajikawa, 2008). Also, more recent studies focused on larger coupled systems are partially reflected in current results (Hassan et al., 2013; Kajikawa et al., 2014). The emerging concept of sustainability science is especially reflected in new scientific approaches towards SD, focusing on inter- and transdisciplinarity, which respond to broader societal expectations and innovative educational perspectives on SD (Dlouhá and Burandt, 2015). 
As pointed out earlier, articles of a specific journal can be classified in Scopus simultaneously under more than one subject (Chadegani et al., 2013). Even considering the possibility that a limited number of journals had a double classification, the distribution of publications of the two groups is clearly outlined. The results also confirms that traditional bibliometric analysis can be dramatically improved with the use of visual tools, such as science maps, thereby reinforcing previous bibliometric studies (Leydesdorff et al., 2015, 2013).

It could be argued that the academics within the group of course participants, which included academics with a consolidated research trajectory and a higher degree of interdisciplinary research, were looking for a wider perspective and understanding of the global challenges relevant to SHD, and its relationship to the field of engineering. However, the analysis shows that diverse profiles of academics of the engineering field, from junior to more consolidated ones, are interested in being trained in SHD. For this reason, identifying and helping interested academics to incorporate SD into their research in all different variations - mono-, inter-, and transdisciplinary - should be included in university policies (Lozano, 2006; Lozano et al., 2013b). This would help to integrate sustainability issues into different levels of the university system (Mcmillin and Dyball, 2009; Ramos et al., 2015; Sterling et al., 2014). The relevance of the publications related to social science of the groups of experts also confirms previous studies. For instance, Segalàs et al. (2012) compared the understanding of sustainability between a group of experts and students of technical universities and concluded that the experts tend to give more value to the social aspect of sustainability. Specifically, this means how sustainability affects humans (social impact, unbalances, future), and how problems of unsustainability can be solved (values, education, and stakeholders) (ibidem).

It is worth highlighting that the broadness of the research of the two groups presented through the maps, in terms of disciplines covered by their research, is tremendously simplified through ARWU rankings, which consider only publications classified in the field of engineering/technology and computer science (ENG) to compile the ranking of engineering institutions. Bearing in mind the high level of internalisation and institutionalisation of ranking in HEI (Hazelkorn, 2014; Locke, 2014), it is likely that in technical universities, characterised by a strong disciplinarity, this trend could represent a further barrier for all academics interested in engaging in SD; this complements the conclusion from other research focusing on SD drivers and barriers at university level (Lozano, 2006; Lozano et al., 2013b; Stephens et al., 2008; Velazquez et al., 2005).

The indexes calculated for both individual researchers and the portfolios of publications of the two groups show that, at a general level, the two groups presented a similar degree of interdisciplinarity. The Shannon index shows that the diversity of publications of the majority of academics in the two groups was substantially similar in term of number of disciplines. In addition, the analysis shows that there is no relationship between the degree of interdisciplinarity and the scientific productivity of those researchers who focusing their scientific publications in disciplines related to social science. The Rao-Stirling index, analogously, presented almost identical values of interdisciplinarity between the two groups analysed. In this case, though, the index also captured the degree of disparity among the disciplines characterising the different subsets of journals of the two groups, relying on the values provided by the distance metrics of science maps, according to Leydesdorff et al. (2014). Within these metrics, the scientific publications related to the disciplines of social science and health sciences were at an equivalent distance from the central core of publications focused on engineering, which is similar for the two groups. It can be easily appreciated, by visualising the 
maps, the specular distribution of the publications of the two groups onto the global map of science.

\section{Conclusions}

During the last decades, growing numbers of HEI have been engaged in integrating SD principles into their functions. Polytechnic universities and engineering faculties have made major progress in this direction. Nevertheless, more effort is needed to advance to the stage of in-depth reforms. The practical and structured orientation, as well as the methods characterising engineering education, make it particularly challenging to promote a cultural shift towards frameworks of knowledge characterising SD, which are defined by uncertainty, complexity, and cultural sensitivity. The success of the policies aimed at integrating SD in the different university functions largely depends on the willingness and the capability of academic staff to engage with and to sustain such processes. For this reason, it is critical to have accurate and reliable information about the academic profile of the academics willing to engage with SD in their academic activities. This can improve the promotion and replication of successful initiatives aimed at empowering academic staff. This study focused specifically on bibliometric features, reflecting the research activity of a community of academics of engineering engaged in SD training practices. The three main conclusions, which may be useful for informing university leaders as well as academic communities of technical universities, are as follows:

First, this study shows that the academics in the field of engineering with proven expertise in SHD present an unusual integration/complementation of their research activity of disciplines related to engineering and social sciences, as well as a high degree of interdisciplinarity. This outcome can have different implications for the promotion of SD in engineering universities. On the one side, these interdisciplinary profiles conjugating expertise in such diverse academic fields can be actively involved in the processes of promotion and assessment of activities related to sustainability in HEI, such as professional development initiatives. On the other side, these profiles can help to foster cultural changes in those universities and faculties engaged in processes aimed at shortening the strong disciplinary dimension characterising engineering academic environments.

Second, academics willing to be trained in SHD present a high degree of interdisciplinarity, and their scientific productivity is specifically related to the academic fields of engineering and health sciences. These characteristics have potential implications for future strategies aimed at identifying and engaging specific academic profiles in sustainability, for example through training initiatives addressed to engineering faculty. Traditionally, the environmental aspects of SD have been particularly relevant in the perception of the academics of engineering and have been the main focus of the promotion of SD and its integration in technical institutions. Medicine-related fields linked with engineering, such as biotechnology, could be a new promoting opportunity to explore. In this sense, the diverse perceptions that academics have about of the nature of $\mathrm{SD}$, and the personal contributions that can be provided starting from a personal expertise, are important drivers for the engagement with SD. This 'interpretational flexibility' of SD (Sammalisto et al., 2015) should be better explored as an opportunity to integrate $\mathrm{SD}$ in engineering.

Third, university rankings may represent a critical barrier to embedding SD in HEI. This study emphasises that rankings might amplify the disciplinary dimension of university performances, 
conditioning academics to align with respective institutional goals. Specifically, in the case of engineering, this can contribute to increasing the disciplinary evaluation of academics and, consequently, to discouraging specific research initiatives not aligned with specific fields or disciplines. For these reasons, further analysis of the outcomes of ranking and their implications for the integration of SD, as well as appropriate policies and mechanisms of faculty rewarding and promotion, are recommended.

\section{Acknowledgments}

The research was conducted in the framework of the European Initiative Global Dimension in Engineering Education, financed by:

- European Commission, Non-State Actors and Local Authorities in Development, Raising public awareness of development issues and promoting development education in the European Union Reference: EuropeAid/131141/C/ACT/MULTI, Contract number: DCINSAED/2012/280-929- Barcelona City Council, Program: Barcelona Solidaria 2013. Grant number: 13ED0046

Funding sources had no involvement in study design, in the collection, analysis, and interpretation of data, in the writing of the report, or in the decision to submit the article for publication.

The authors would like to thank Dr. Ismael Ràfols, Ingenio CSIC-UPV, and Dr. Loet Leydesdorff, University of Amsterdam, for their valuable support on journal maps and interactive overlays used in this article.

\section{References}

Abrizah, A., Zainab, A.N., Kiran, K., Raj, R.G., 2013. LIS journals scientific impact and subject categorization: A comparison between Web of Science and Scopus. Scientometrics 94, 721-740. doi:10.1007/s11192-012-0813-7

Absell, C.D., 2015. The Lexicon of Development: A Quantitative History of the Language of Development Studies. Iberoam. J. Dev. Stud. 4, 4-34.

ARWU, 2015. Academic Ranking of World Universities [WWW Document]. URL http://www.shanghairanking.com/

Barth, M., Rieckmann, M., 2012. Academic staff development as a catalyst for curriculum change towards education for sustainable development: An output perspective. J. Clean. Prod. 26, 28-36. doi:10.1016/j.jclepro.2011.12.011

Binder, C.R., Absenger-Helmli, I., Schilling, T., 2015. The reality of transdisciplinarity: a framework-based self-reflection from science and practice leaders. Sustain. Sci. 10, 545562. doi:10.1007/s11625-015-0328-2

Boni, A., Gasper, D., 2012. Rethinking the Quality of Universities: How Can Human Development Thinking Contribute? J. Hum. Dev. Capab. 13, 451-470. doi:10.1080/19452829.2012.679647

Boni, A., Pérez-Foguet, A., 2008. Introducing development education in technical universities: 
successful experiences in Spain. Eur. J. Eng. Educ. 33, 343-354.

doi:10.1080/03043790802088723

Boni, A., Sastre, J.J., Calabuig, C., 2015. Educating Engineers for the Public Good Through International Internships: Evidence from a Case Study at Universitat Politècnica de València. Sci. Eng. Ethics. doi:10.1007/s11948-015-9728-Z

Boyack, K.W., Klavans, R., Börner, K., 2005. Mapping the backbone of science. Scientometrics 64, 351-374. doi:10.1007/s11192-005-0255-6

Carayol, N., Nguyen Thi, T.U., 2005. Why do academic scientists engage in interdisciplinary research?, in: Research Evaluation. pp. 70-79.

Cebrián, G., Grace, M., Humphris, D., 2015. Academic staff engagement in education for sustainable development. J. Clean. Prod. 106, 1-16. doi:10.1016/j.jclepro.2014.12.010

Chadegani, A.A., Salehi, H., Yunus, M.M., Farhadi, H., Fooladi, M., Farhadi, M., Ebrahim, N.A., Aghaei Chadegani, A., Salehi, H., Md Yunus, M.M., Farhadi, H., Fooladi, M., Farhadi, M., Ale Ebrahim, N., 2013. A comparison between two main academic literature collections: Web of science and scopus databases. Asian Soc. Sci. 9, 18-26. doi:10.5539/ass.v9n5p18

Clark, W.C., Dickson, N.M., 2003. Sustainability science: the emerging research program. Proc. Natl. Acad. Sci. U. S. A. 100, 8059-8061. doi:10.1073/pnas.1231333100

Collins, F.L., Park, G.-S., 2015. Ranking and the multiplication of reputation: reflections from the frontier of globalizing higher education. High. Educ. doi:10.1007/s10734-015-9941-3

Dlouhá, J., Burandt, S., 2015. Design and evaluation of learning processes in an international sustainability oriented study programme. in search of a new educational quality and assessment method, in: Journal of Cleaner Production. pp. 247-258.

doi:10.1016/j.jclepro.2014.09.096

Dlouhá, J., Huisingh, D., Barton, A., 2013. Learning networks in higher education: universities in search of making effective regional impacts. J. Clean. Prod. 49, 5-10. doi:10.1016/j.jclepro.2013.01.034

Fenner, R.A., Ainger, C.M., Cruickshank, H.J., Guthrie, P.M., 2005. Embedding sustainable development at Cambridge University Engineering Department. Int. J. Sustain. High. Educ. 6, 229-241. doi:10.1108/14676370510607205

Ferrer-Balas, D., Adachi, J., Banas, S., Davidson, C.I., Hoshikoshi, A., Mishra, A., Motodoa, Y., Onga, M., Ostwald, M., 2008. An international comparative analysis of sustainability transformation across seven universities. Int. J. Sustain. High. Educ. 9, 295-316. doi:10.1108/14676370810885907

Filho, W.L., 2011. About the Role of Universities and Their Contribution to Sustainable Development. High. Educ. Policy 24, 427-438. doi:10.1057/hep.2011.16

Filho, W.L., 2000. Dealing with misconceptions on the concept of sustainability. Int. J. Sustain. High. Educ. 1, 9-19. doi:10.1108/1467630010307066

Gaziulusoy, A.I., Boyle, C., 2013. Proposing a heuristic reflective tool for reviewing literature in transdisciplinary research for sustainability. J. Clean. Prod. 48, 139-147. doi:10.1016/j.jclepro.2012.04.013

GDEE, 2015. Case studies for developing globally responsible engineers [WWW Document]. URL http://upcommons.upc.edu/handle/2117/88905 
GDEE (Ed.), 2014. Global Dimension in Engineering Education [WWW Document]. URL http://upcommons.upc.edu/handle/2117/26502

Gibbons, M., 1999. Science's new social contract with society. Nature 402, 81-84. doi: $10.1038 / 35011576$

Halbe, J., Adamowski, J., Pahl-Wostl, C., 2015. The role of paradigms in engineering practice and education for sustainable development. J. Clean. Prod. 106, 272-282.

doi:10.1016/j.jclepro.2015.01.093

Harzing, A.W., Alakangas, S., 2016. Google Scholar, Scopus and the Web of Science: a longitudinal and cross-disciplinary comparison. Scientometrics 106, 787-804. doi:10.1007/s11192-015-1798-9

Hassan, S.-U.U., Haddawy, P., Zhu, J., 2013. A bibliometric study of the world's research activity in sustainable development and its sub-areas using scientific literature, Scientometrics. Kluwer Academic Publishers. doi:10.1007/s11192-013-1193-3

Hazelkorn, E., 2015. Rankings and the Reshaping of Higher Education: The Battle for WorldClass Excellence: Second Edition, Rankings and the Reshaping of Higher Education: The Battle for World-Class Excellence: Second Edition. Palgrave Macmillan UK, London. doi:10.1057/9781137446671

Hazelkorn, E., 2014. Reflections on a Decade of Global Rankings: What we've learned and outstanding issues. Eur. J. Educ. 49, 12-28. doi:10.1111/ejed.12059

Heinrichs, H., Martens, P., Michelsen, G., Wiek, A. (Eds.), 2016. Sustainability Science. Springer Netherlands, Dordrecht. doi:10.1007/978-94-017-7242-6

Holm, T., Sammalisto, K., Grindsted, T.S., Vuorisalo, T., 2015. Process framework for identifying sustainability aspects in university curricula and integrating education for sustainable development. J. Clean. Prod. 106, 164-174. doi:10.1016/j.jclepro.2015.04.059

Holmberg, J., Svanström, M., Peet, D.-J., Mulder, K., Ferrer-Balas, D., Segalàs, J., 2008. Embedding sustainability in higher education through interaction with lecturers: Case studies from three European technical universities. Eur. J. Eng. Educ. 33, 271-282. doi:10.1080/03043790802088491

Hoover, E., Harder, M.K., 2014. What lies beneath the surface? The hidden complexities of organizational change for sustainability in higher education. J. Clean. Prod. 106, 175-188. doi:10.1016/j.jclepro.2014.01.081

Hugé, J., Block, T., Waas, T., Wright, T., Dahdouh-Guebas, F., 2016. How to walk the talk? Developing actions for sustainability in academic research. J. Clean. Prod. 137, 83-92. doi:10.1016/j.jclepro.2016.07.010

Kajikawa, Y., 2008. Research core and framework of sustainability science. Sustain. Sci. 3, 215-239. doi:10.1007/s11625-008-0053-1

Kajikawa, Y., Tacoa, F., Yamaguchi, K., 2014. Sustainability science: the changing landscape of sustainability research. Sustain. Sci. 9, 431-438. doi:10.1007/s11625-014-0244-x

Krizek, K.J., Newport, D., White, J., Townsend, A.R., 2012. Higher education's sustainability imperative: how to practically respond? Int. J. Sustain. High. Educ. 13, 19-33. doi:10.1108/14676371211190281

Lang, D.J., Wiek, A., Bergmann, M., Stauffacher, M., Martens, P., Moll, P., Swilling, M., Thomas, C.J., 2012. Transdisciplinary research in sustainability science: practice, 
principles, and challenges. Sustain. Sci. 7, 25-43. doi:10.1007/s11625-011-0149-x

Lasda Bergman, E.M., 2012. Finding Citations to Social Work Literature: The Relative Benefits of Using Web of Science, Scopus, or Google Scholar. J. Acad. Librariansh. 38, 370-379. doi:10.1016/j.acalib.2012.08.002

Lazzarini, B., Pérez-Foguet, A., Boni, A., n.d. Key characteristics of academics promoting Sustainable Human Development within engineering studies (under revision). J. Clean. Prod.

Leydesdorff, L., de Moya-Anegón, F., Guerrero-Bote, V.P., 2015. Journal maps, interactive overlays, and the measurement of interdisciplinarity on the basis of Scopus data (19962012). J. Assoc. Inf. Sci. Technol. 66, 1001-1016. doi:10.1002/asi.23243

Leydesdorff, L., Rafols, I., 2011. Indicators of the interdisciplinarity of journals: Diversity, centrality, and citations. J. Informetr. 5, 87-100. doi:10.1016/j.joi.2010.09.002

Leydesdorff, L., Rafols, I., Chen, C., 2013. Interactive overlays of journals and the measurement of interdisciplinarity on the basis of aggregated journal-journal citations. J. Am. Soc. Inf. Sci. Technol. 64, 2573-2586. doi:10.1002/asi.22946

Locke, W., 2014. The Intensification of Rankings Logic in an Increasingly Marketised Higher Education Environment. Eur. J. Educ. 49, 77-90. doi:10.1111/ejed.12060

Lozano, F.J., Lozano, R., 2014. Developing the curriculum for a new Bachelor's degree in Engineering for Sustainable Development. J. Clean. Prod. 64, 136-146. doi:10.1016/j.jclepro.2013.08.022

Lozano, R., 2006. Incorporation and institutionalization of SD into universities: breaking through barriers to change. J. Clean. Prod. 14, 787-796. doi:10.1016/j.jclepro.2005.12.010

Lozano, R., Ceulemans, K., Alonso-Almeida, M., Huisingh, D., Lozano, F.J., Waas, T., Lambrechts, W., Lukman, R., Hugé, J., 2015. A review of commitment and implementation of sustainable development in higher education: results from a worldwide survey. J. Clean. Prod. 108, 1-18. doi:10.1016/j.jclepro.2014.09.048

Lozano, R., Lozano, F.J., Mulder, K., Huisingh, D., Waas, T., 2013a. Advancing Higher Education for Sustainable Development: International insights and critical reflections. J. Clean. Prod. 48, 3-9. doi:10.1016/j.jclepro.2013.03.034

Lozano, R., Lukman, R., Lozano, F.J., Huisingh, D., Lambrechts, W., 2013b. Declarations for sustainability in higher education: becoming better leaders, through addressing the university system. J. Clean. Prod. 48, 10-19. doi:10.1016/j.jclepro.2011.10.006

Lubchenco, J., 1998. Entering the Century of the Environment: A New Social Contract for Science. Science (80-. ). 279, 491-497. doi:10.1126/science.279.5350.491

Lukman, R., Krajnc, D., Glavič, P., 2010. University ranking using research, educational and environmental indicators. J. Clean. Prod. 18, 619-628. doi:10.1016/j.jclepro.2009.09.015

Max-Neef, M.A., 2005. Foundations of transdisciplinarity. Ecol. Econ. 53, 5-16. doi:10.1016/j.ecolecon.2005.01.014

McCormick, K., Neij, L., Mont, O., Ryan, C., Rodhe, H., Orsato, R., 2016. Advancing sustainable solutions: An interdisciplinary and collaborative research agenda. J. Clean. Prod. 123, 1-4. doi:10.1016/j.jclepro.2016.01.038

Mcmillin, J., Dyball, R., 2009. Developing a Whole-of-University Approach to Educating for 
Sustainability: Linking Curriculum, Research and Sustainable Campus Operations. J. Educ. Sustain. Dev. 3, 55-64. doi:10.1177/097340820900300113

Miller, T.R., Wiek, A., Sarewitz, D., Robinson, J., Olsson, L., Kriebel, D., Loorbach, D., 2014. The future of sustainability science: A solutions-oriented research agenda. Sustain. Sci. 9, 239-246. doi:10.1007/s11625-013-0224-6

Minasny, B., Hartemink, A.E., McBratney, A., Jang, H.-J., 2013. Citations and the h index of soil researchers and journals in the Web of Science, Scopus, and Google Scholar. PeerJ 1, e183. doi:10.7717/peerj.183

Morrissey, J., 2013. Regimes of performance: practices of the normalised self in the neoliberal university. Br. J. Sociol. Educ. 36, 614-634. doi:10.1080/01425692.2013.838515

Mulder, K.F., Segalàs, J., Ferrer-Balas, D., 2012. How to educate engineers for/in sustainable development Ten years of discussion, remaining challenges. Int. J. Sustain. High. Educ. 13, 211-218. doi:10.1108/14676371211242535

Müller-Christ, G., Sterling, S., van Dam-Mieras, R., Adomßent, M., Fischer, D., Rieckmann, M., 2014. The role of campus, curriculum, and community in higher education for sustainable development - a conference report. J. Clean. Prod. 62, 134-137. doi:10.1016/j.jclepro.2013.02.029

National Academies, 2004. Facilitating Interdisciplinary Research. National Academies Press, Washington, D.C. doi:10.17226/11153

Pérez-Foguet, A., 2008. Educative experiences through cooperation for development activities, in: "Higher Education in the World 3, Higher Education: New Challenges and Emerging Roles for Human and Social Development." Palgrave Macmillan Ltd.

Pérez-Foguet, A., Lazzarini, B., Giné, R., Velo, E., Boni, A., Sierra-Castañer, M., Zolezzi, G., Trimingham, R., 2017. Promoting sustainable human development in engineering: Assessment of online courses within continuing professional development strategies. J. Clean. Prod. doi:https://doi.org/10.1016/j.jclepro.2017.06.244

Pérez-Foguet, A., Oliete-Josa, S., Saz-Carranza, A., 2005. Development education and engineering: A framework for incorporating reality of developing countries into engineering studies. Int. J. Sustain. High. Educ. 6, 278-303. doi:10.1108/14676370510607241

Porter, A.L., Rafols, I., 2009. Is science becoming more interdisciplinary? Measuring and mapping six research fields over time. Scientometrics 81, 719-745. doi:10.1007/s11192$008-2197-2$

Quental, N., Lourenço, J.M., 2012. References, authors, journals and scientific disciplines underlying the sustainable development literature: A citation analysis. Scientometrics 90, 361-381. doi:10.1007/s11192-011-0533-4

Rafols, I., Meyer, M., 2009. Diversity and network coherence as indicators of interdisciplinarity: case studies in bionanoscience. Scientometrics 82, 263-287. doi:10.1007/s11192-009-0041-y

Ramos, T.B., Caeiro, S., van Hoof, B., Lozano, R., Huisingh, D., Ceulemans, K., 2015. Experiences from the implementation of sustainable development in higher education institutions: Environmental Management for Sustainable Universities. J. Clean. Prod. 106, 3-10. doi:10.1016/j.jclepro.2015.05.110

Rauhvargers, A., 2014. Where are the global rankings leading us? An analysis of recent 
methodological changes and new developments. Eur. J. Educ. 49, 29-44. doi:10.1111/ejed.12066

Roales-Nieto, J.G., O’Neill, B., 2012. A comparative study of journals quality based on web of science, scopus and google scholar: A case study with IJP\&amp;PT. Int. J. Psychol. Psychol. Ther. 12, 453-479.

Sammalisto, K., Sundström, A., Holm, T., 2015. Implementation of sustainability in universities as perceived by faculty and staff - a model from a Swedish university. J. Clean. Prod. 106, 45-54. doi:10.1016/j.jclepro.2014.10.015

Sanz-Menéndez, L., Bordons, M., Zulueta, M.A., 2001. Interdisciplinarity as a multidimensional concept: Its measure in three different research areas. Res. Eval. 10, 4758.

Science-Metrix, 2016. Science-Metrix [WWW Document]. URL http://www.sciencemetrix.com/en/classification (accessed 6.16.16).

Segalàs, J., Ferrer-Balas, D., Mulder, K.F., 2010. What do engineering students learn in sustainability courses? The effect of the pedagogical approach. J. Clean. Prod. 18, 275284. doi:10.1016/j.jclepro.2009.09.012

Segalàs, J., Ferrer-Balas, D., Svanström, M., Lundqvist, U., Mulder, K.F., 2009. What has to be learnt for sustainability? A comparison of bachelor engineering education competences at three European universities. Sustain. Sci. 4, 17-27. doi:10.1007/s11625-009-0068-2

Segalàs, J., Mulder, K.F., Ferrer-Balas, D., 2012. What do EESD “experts” think sustainability is? Which pedagogy is suitable to learn it? Int. J. Sustain. High. Educ. 13, 293-304. doi:10.1108/14676371211242599

Sen, A., 1999. Development as Freedom. Oxford Press 1-50. doi:10.1215/0961754X-9-2-350

Stephens, J.C., Hernandez, M.E., Román, M., Graham, A.C., Scholz, R.W., 2008. Higher education as a change agent for sustainability in different cultures and contexts. Int. J. Sustain. High. Educ. 9, 317-338. doi:10.1108/14676370810885916

Sterling, S., Maxey, L., Luna, H., Parkin, S., 2014. The Sustainable University: Progress and Prospects, Journal of Education for Sustainable Development. Routledge. doi: $10.1177 / 0973408214526494$

Stirling, A., 2007. A general framework for analysing diversity in science, technology and society. J. R. Soc. Interface 4, 707-19. doi:10.1098/rsif.2007.0213

Svanström, M., Palme, U., Wedel, M.K., Carlson, O., Nyström, T., Edén, M., 2012. Embedding of ESD in Engineering Education -Experiences from Chalmers University of Technology. Int. J. Sustain. High. Educ. 13, 279-292. doi:10.1108/14676371211242580

Takeuchi, K., Komiyama, H., 2006. Sustainability science: building a new discipline. Sustain. Sci. 1, 1-6. doi:10.1007/s11625-006-0007-4

Tomlinson, M., 2015. The Impact of Market-Driven Higher Education on Student-University Relations: Investing, Consuming and Competing. High. Educ. Policy 29, 149-166. doi: $10.1057 /$ hep. 2015.17

Torres-Salinas, D., Lopez-Cózar, E.D., Jiménez-Contreras, E., 2009. Ranking of departments and researchers within a university using two different databases: Web of science versus scopus. Scientometrics 80, 761-774. doi:10.1007/s11192-008-2113-9 
United Nations, 2015a. Millennium Development Goals Report 2015, United Nations.

United Nations, 2015b. General Assembly resolution 70/1, Transforming our world: the 2030 Agenda for Sustainable Development, A/RES/70/1 (25/09/2015).

van Leeuwen, T., Tijssen, R., 2000. Interdisciplinary dynamics of modern science: analysis of cross-disciplinary citation flows. Res. Eval. 9, 183-187.

doi:10.3152/147154400781777241

Velazquez, L., Munguia, N., Platt, A., Taddei, J., 2006. Sustainable university: what can be the matter? J. Clean. Prod. 14, 810-819. doi:10.1016/j.jclepro.2005.12.008

Velazquez, L., Munguia, N., Sanchez, M., 2005. Deterring sustainability in higher education institutions: An appraisal of the factors which influence sustainability in higher education institutions 6, 383-391. doi:10.1108/14676370510623865

Verhulst, E., Lambrechts, W., 2014. Fostering the incorporation of sustainable development in higher education. Lessons learned from a change management perspective. J. Clean. Prod. 106, 189-204. doi:10.1016/j.jclepro.2014.09.049

Vieira, E.S., Gomes, J.A.N.F., 2009. A comparison of Scopus and Web of science for a typical university. Scientometrics 81, 587-600. doi:10.1007/s11192-009-2178-0

von Blottnitz, H., Case, J.M., Fraser, D.M., 2015. Sustainable development at the core of undergraduate engineering curriculum reform: a new introductory course in chemical engineering. J. Clean. Prod. 106, 300-307. doi:10.1016/j.jclepro.2015.01.063

Waas, T., Verbruggen, A., Wright, T., 2010. University research for sustainable development: definition and characteristics explored. J. Clean. Prod. 18, 629-636. doi:10.1016/j.jclepro.2009.09.017

Wagner, C.S., Roessner, J.D., Bobb, K., Klein, J.T., Boyack, K.W., Keyton, J., Rafols, I., Börner, K., 2011. Approaches to understanding and measuring interdisciplinary scientific research (IDR): A review of the literature. J. Informetr. 5, 14-26. doi:10.1016/j.joi.2010.06.004

Wals, A.E.J., 2014. Sustainability in higher education in the context of the UN DESD: a review of learning and institutionalization processes. J. Clean. Prod. 62, 8-15. doi:10.1016/j.jclepro.2013.06.007

White, R.M., 2015. Who am I? The Role(s) of an Academic at a "Sustainable University," in: Leal Filho, W., Brandli, L., Kuznetsova, O., Paço, A.M.F. d. (Eds.), Integrative Approaches to Sustainable Development at University Level. Springer International Publishing, pp. 675-686. doi:10.1007/978-3-319-10690-8

Xu, L., Marinova, D., 2013. Resilience thinking: A bibliometric analysis of socio-ecological research. Scientometrics 96, 911-927. doi:10.1007/s11192-013-0957-0

Yarime, M., Trencher, G., Mino, T., Scholz, R.W., Olsson, L., Ness, B., Frantzeskaki, N., Rotmans, J., 2012. Establishing sustainability science in higher education institutions: towards an integration of academic development, institutionalization, and stakeholder collaborations. Sustain. Sci. 7, 101-113. doi:10.1007/s11625-012-0157-5 